\title{
Limites e possibilidades da educação formal: um debate entre Paulo Freire e Ivan Illich
}

\author{
Roberta Baessa Estimado e \\ João Luís Lemos de Paula Santos
}

\section{Resumo:}

Neste artigo, discutiremos a dimensão institucional da crise da educação a partir de dois autores: Ivan Illich e Paulo Freire. Tendo como base o registro de um debate realizado entre eles e algumas de suas principais publicações das décadas de I960 e I970, analisaremos suas formulações e críticas acerca do modelo escolar e da institucionalização educacional. Depois dessa primeira aproximação, buscaremos possíveis relações de convergência e divergência entre Illich e Freire. Por fim, inserindo-os no quadro mais geral de debates sobre a crise da educação - desde o século XX até mais recentemente -, refletiremos sobre a atualidade das contribuições desses dois pensadores e os limites e as possibilidades da educação formal.

Palavras-chave: Crise da Educação - Educação Formal - Desescolarização Conscientização 


\section{Introdução: a crise da educação}

A escola, enquanto invenção da modernidade e instância educativa especializada, atravessou tempos históricos apresentando-se, atualmente, permeada por desilusões e incertezas. Os paradoxos que tangem o formato escolar perpassam, nas discussões acerca da crise da educação, diversas ideias e pontos de vista distintos sobre o seu presente e futuro. Se, atualmente, mesmo nos chamados países em desenvolvimento, a escola já é, na maior parte dos casos, obrigatória e acessível para a maioria da população, como podemos repensar sua função na contemporaneidade?

Quando a escola deixou de ser uma promessa e tornou-se real, o otimismo devido à expectativa de que a escolarização traria igualdade e generalização do bem-estar não demorou muito para se esvair. Nesse sentido, as reflexões de educadores e estudiosos, mais intensamente a partir do final dos anos I960, já elucidavam os mais diversos aspectos que justificariam essa suposta crise.

De modo geral, algumas problemáticas em particular recebem maior destaque no bojo dessas reflexões. Em relação à autoridade, por exemplo, muito se argumenta acerca de sua perda e da desvalorização das tradições como ponto fulcral da crise da educação. Além disso, são frequentes as afirmações no sentido de que ela estaria intrinsecamente associada à expansão da economia capitalista e, por conseguinte, de seus conflitos e crises nas sociedades contemporâneas.

Entretanto, sem desprezar seus aspectos políticos, ideológicos, de valores e até mesmo de tradições, que são, inclusive, essenciais nesse debate, optamos por centrar nosso objeto de estudo e reflexão em uma dimensão específica: a crise do modelo escolar - e, particularmente, a sua ineficiência e incapacidade de promover uma educação igualitária. A dúvida é: será que vivemos uma crise de dissolução da escola, que nos permitirá criar novas possibilidades - institucionais ou não - de construção do conhecimento ou protagonizamos uma crise com potencial de reconstituir o modelo escolar a partir de novas concepções?

Para uma aproximação inicial ao debate, que já se perpetua por mais de meio século, elegemos dois importantes teóricos da educação das décadas de 1960 e I970, que tiveram seus estudos lidos e repercutidos permanentemente ao longo desta última geração: Paulo Freire e Ivan Illich. Freire, educador brasileiro, que se destacou por seu trabalho pioneiro na alfabetização de adultos e em educação popular. Illich, pensador austríaco, crítico às instituições e dono de estudos nas mais diversas áreas do conhecimento. 
Além de serem autores da mesma geração e terem vivido e escrito suas obras quase que concomitantemente, eles circulavam em alguns espaços comuns a ambos e, portanto, integravam um campo de interação intelectual com certas problemáticas e referenciais teóricos próximos. A escolha da composição desse debate parte de um documento concreto, uma obra produzida a partir do encontro dos dois teóricos em Genebra, na Suíça, em uma das séries de debates promovidas pelo Centro Intercultural de Documentação (CIDOG), acerca de alternativas para a educação.

A partir desse diálogo entre Freire e Illich, percorremos algumas das principais obras e estudos desses autores no intuito de encontrar um fio condutor das convergências e divergências de seus pensamentos e considerações acerca da educação e do sistema escolar em si mesmo. Assim, a partir das suas formulações sobre educação formal, tentaremos trazer elementos das obras estudadas para que possamos questionar como esses autores contribuíram para o complexo quadro conceitual sobre a crise da escola e, mais propriamente, em métodos e possíveis soluções para enfrentá-la.

\section{Ivan Illich: da sociedade desescolarizada à convivencialidade}

Ivan Illich iniciou suas primeiras reflexões acerca da desescolarização através de suas discussões com Everett Reimer, em I958 (ILLICH 2006, v. I). ${ }^{\text {I }}$ Foi no GIDOC que os autores se conheceram e tentaram colocar em prática suas ideias acerca da educação desescolarizada. Tratava-se, naquele momento, de um espaço para o encontro de diversos intelectuais - em especial, latino-americanos - com o intuito de debater questões ligadas à educação e à cultura.

A partir disso, Illich começou a produzir diversos escritos sobre a temática da educação, em sua maior parte na forma de pequenos artigos, diálogos com outros intelectuais, e alguns pequenos discursos. Seus primeiros textos sobre a escola já denunciavam a burocratização do sistema escolar e suas desigualdades de acesso, assim como anunciavam suas ideias para a formação de redes educativas partilhadas por todos.

I No capítulo introdutório da obra, Illich reforça a importância de Reimer nas suas indagações acerca da obrigatoriedade de frequentar a escola. 
Entretanto, o ápice da sua produção a respeito da desescolarização seria, sobretudo, La sociedad desescolarizada, ${ }^{2}$ publicada pela primeira vez em inglês, no ano de 1970 . É nessa obra que o autor faria a sua maior crítica à institucionalização da educação nas sociedades contemporâneas, o que significava, para ele, que a escola era a monopolizadora exclusiva do saber.

Seu texto é introduzido com uma explicação sobre por que devemos desinstalar a escola. Ele defende que esta tem um efeito antieducacional sobre a sociedade, visto que a educação obrigatória, em termos econômicos, é completamente impraticável. ${ }^{3}$ Desse modo, inicialmente já haveria uma polarização social em função da própria escola entre os que podem e os que não podem frequentá-la.

Ele acredita sim que devemos almejar a igualdade de oportunidades na educação, mas que isso não significa, de modo algum, a obrigatoriedade do ensino escolar, posto que aprendemos com nossas vivências, em sua maior parte fora da escola. Com isso, restringir os direitos educacionais para uso exclusivo dessa instituição garante apenas uma sociedade em que, mais do que o próprio conhecimento, a importância central será sempre atribuída para os diplomas que acumulamos.

Sua definição de escola permeia um espaço institucionalizado que requer assistência e tempo integral a um currículo obrigatório, com idade delimitada e a necessidade instituída da presença de um professor; com a premissa inquestionável de que o lugar das crianças é na escola e que somente nela é possível aprender. Assim, é ensinada a necessidade de ser ensinado, criando-se a dicotomia entre os discriminados e os privilegiados.

Por isso, defende que elas são um falso serviço público: sua concepção estaria baseada na ideia de que existe um segredo para toda e qualquer nuance da vida, e que dependemos do conhecimento desses segredos para viver com qualidade. Todavia, somente o professor seria capaz de revelá-los, de modo sucessivo e ordenado. Por isso, seríamos eternos reféns dessa instituição e de seu ensino curricular.

Partindo do pressuposto de que o ser humano deve ser agente do seu conhecimento, isto é, ser o principal responsável pela sua busca, Illich com-

2 Apesar de existirem traduções da obra para o português, optamos por utilizá-la em espanhol, especialmente pelo erro na tradução de seu título. A obra foi traduzida, tanto no português quanto no francês, como Sociedade sem escolas, perdendo seu sentido original.

3 Numericamente, Illich apresenta dados acerca dos gastos escolares nos Estados Unidos, defendendo que, na maior parte dos casos, seriam necessários quase o triplo do que é gasto atualmente para garantir o que se chama de educação igualitária e obrigatória para todos. 
preende que somente ampliando as relações que capacitam o homem a definir-se a si mesmo pela aprendizagem e contribuindo com a aprendizagem dos outros será possível uma nova e real possibilidade. Nomeia esta forma alternativa de teias de aprendizagem, ou seja, o que ele entende enquanto aprendizagem automotivada.

Para conformar as teias de aprendizagem, ele propõe sua divisão em quatro esferas: o serviço de consulta a objetos educacionais - museus, teatros, laboratórios, bibliotecas, entre outros -, o intercâmbio de habilidades - em que as pessoas relacionem suas aptidões e troquem conhecimentos -, o encontro com colegas - parceiros de um tema de pesquisa ou de interesse comum -, e o serviço de consulta a educadores independentes - com função de manejar os intercâmbios educacionais, orientar pais e estudantes no uso dessas redes de aprendizagem e compreender as jornadas exploratórias mais complexas e difíceis.

Portanto, escolarização e educação tornaram-se, para Illich, conceitos paradoxais. Se desescolarizar significava abolir o poder de obrigar as pessoas a frequentarem a escola, a educação estaria na liberdade em acessar os meios de obtenção do conhecimento e promover a aprendizagem em redes reais de serviço público. Sua denúncia da educação institucionalizada em forma de mercadoria ecoou internacionalmente na década de I960, incitando cada vez mais as discussões acerca da crise da escola.

Em I974, poucos anos após a publicação da sua obra clássica, Illich amplia seu objeto de pesquisa em um trabalho que transcende as temáticas educacionais, conformando-se em uma perspectiva ampliada das relações do homem com o trabalho e da própria organização social. Em uma nova obra, partindo de uma autocrítica a algumas de suas reflexões anteriores, passa a defender que a desescolarização somente não seria capaz de transformar a sociedade. Trata-se de La convivencialidad, em que o pensador propõe novos horizontes de transformação social.

Nesse trabalho, Illich defende o fim do modo de produção industrial e de todas as instituições que o mantém funcionando, dentre elas a escola. Esse seria, a priori, o método para se alcançar seu ideal utópico: a sociedade convivencial. Segundo o autor: "Llamo sociedad convivencial a aquella en que la herramienta moderna está al servicio de la persona integrada a la colectividad y no al servicio de un cuerpo de especialistas. Convivencial es la sociedad en que el hombre controla la herramienta" (ILLICH 2006, p. 374).

Além da escola, trabalha com exemplos cotidianos, como a saúde e a própria medicina. Entende que a ferramenta dos médicos, por mais simples que seja, tornou-se uma mercadoria em um sistema em desenvolvimento, per- 
mitindo que eles possam conservar o monopólio completo do saber. Assim, tornam as pessoas dependentes de seus serviços e alienadas das informações a respeito da sua própria saúde.

Pensa que o fracasso das empresas modernas fora, justamente, a substituição dos homens pelas máquinas, visto que essas provocaram uma relação de inversão: o homem passou a ser escravo da máquina, e a máquina, senhora do homem. Compreende que não é possível extinguir as ferramentas modernas, pois são necessárias para o trabalho humano, mas defende que a lógica das instituições deve ser invertida, almejando reconstituir a sociedade em vistas da convivencialidade.

Dessa forma, Illich anuncia uma crise das instituições, que acredita já estar se conformando e ser a única que poderia nos levar a um novo estado de consciência. Com isso, o homem voltaria a depender de seus pares, deixando de ser escravo da energia e da burocracia. Além disso, acredita que a exploração que ocorre do homem pela ferramenta deixará de existir, uma vez que este retomará sua condição de sujeito.

O autor é veementemente contrário ao crescimento industrial, pois defende que somente assim será possível transitar para uma sociedade em que o trabalho, a recreação e a política favoreçam a aprendizagem - o que significa, grosso modo, uma sociedade liberta da inerência dos modelos de educação formal. Assim, a aprendizagem se daria na vivência da própria cultura, enquanto processo permanente.

Por isso, pensa que os diversos modos de produção devem coexistir na sociedade, desmantelando o monopólio da indústria. Somente assim outras formas de produção serão valorizadas, de modo que as pessoas tenham liberdade para escolher as formas de produção que pretendem vivenciar, não se mantendo escravizadas pela ferramenta. Do mesmo modo, devem ser valorizadas outras formas de aprendizagem além da escolarizada, para que todos sejam livres para escolher como aprender e tenham acesso às ferramentas que lhe permitam a aprendizagem.

Assim, a utopia convivencial não excluiria totalmente as instituições, permitindo, dessa forma, a existência de escolas, desde que não mais enquanto monopolizadoras do saber e responsáveis pelo controle social. Possivelmente devido ao contexto ideológico em que suas ideias estavam inseridas, Illich e sua sociedade convivencial não tenham atingido a repercussão merecida, entretanto, é inegável que discussões extremamente atuais já tivessem sido anunciadas há quase meio século. 


\section{Paulo Freire: da educação como prática para a liberdade à pedagogia do oprimido}

Paulo Freire também será um crítico influente das formas tradicionais de educação e aprendizagem. Na segunda metade da década de I960, enquanto exilado político perseguido pela ditadura brasileira, Freire publica seus dois primeiros livros, Educação como prática da liberdade (I967) e Pedagogia do Oprimido (I970), nos quais ele parece estabelecer algumas bases fundamentais para a compreensão do conjunto de sua obra. Assim, centraremos nossa análise subsequente sobre o autor nesses dois livros - embora não desconsideremos seus escritos posteriores -, e levantaremos alguns de seus conceitos fundamentais buscando analisar as mudanças e permanências entre as elaborações das duas obras referentes à problemática proposta.

Um conceito para a qual de início devemos nos atentar e que perpassa, de certa maneira, o conjunto da obra de Paulo Freire é o de vocação ontológica do ser humano. Para ele, o ser humano teria certas características fundamentais necessárias para sua plena realização, ou seja, sua humanização. Assim, na sua plenitude, seria um ser de busca, criativo, sujeito histórico, que se integra à realidade vivida, com consciência de si e de ser inacabado. A partir de sua condição de sujeito, seria um ser transformador do mundo. Sua humanização, entretanto, não seria algo alheio às condições de sua realidade histórica e nem algo que se desse mecanicamente, devido à sua própria característica de busca e inacabamento.

Griticando abordagens mecanicistas, Freire defende que subjetividade e objetividade se constituiriam em relação dialética, de forma indissociável. Desse modo, a negação da humanização, ou seja, a desumanização, seria também uma possibilidade histórica através de relações sociais de opressão, embora não fosse vocação do ser humano. A relação de opressão dividiria opressores e oprimidos, ambos desumanizados por ela, porém de formas diferentes: o primeiro negando a humanização ao segundo e assim negando a si próprio, e o segundo tendo sua humanidade negada.

É importante salientar, porém, que a humanização não seria algo previamente determinado e dado como natural, pelo qual os seres humanos deveriam esperar até que algo transformasse objetivamente a sociedade opressora. Ela partiria já da busca da condição de sujeito na própria situação de opressão e não apenas esperando um momento futuro da superação desta: seria realizada a partir da busca pelo ser mais (FREIRE I987, p. 30).

Podemos perceber logo nessa primeira aproximação que a preocupação central de Paulo Freire está nas próprias relações sociais e nas condições históricas dos seres humanos, e não especificamente em instituições criadas por 
elas, como as escolas ou a existência de um sistema educacional institucionalizado, apesar destas também estarem envolvidas em suas críticas. Sua abordagem, nesse sentido, é em como esses modelos criados se situam nas relações sociais e históricas das quais fazem parte.

Para Paulo Freire, não existe um modelo de educação ideal e a-histórico: a educação serviria a algo em determinado momento histórico e, por isso, seria também criada e recriada por seus sujeitos, educadores e educandos. Diz ele: "Não há educação fora das sociedades humanas e não há homem no vazio" (id. I974, p. 35). Nada mais normal, portanto, que Paulo Freire alterasse suas formas de pensar projetos de educação, mesmo mantendo linhas gerais de suas elaborações teóricas. Não poderia ser diferente entre Educação como prática da liberdade e Pedagogia do Oprimido, embora as obras tenham sido publicadas em datas próximas.

É possível afirmar que, em Educação como prática da liberdade, Paulo Freire fez uma análise e um balanço de suas experiências pedagógicas e políticas no período anterior ao golpe militar de I964 e logo após o golpe, com sua prisão e exílio. Sua preocupação acerca do processo em curso no Brasil anterior ao golpe - momento caracterizado por ele como de transição (id. ibid., pp. 47-48) - refere-se aos rumos a serem tomados pela sociedade brasileira: o final dessa transição, marcada pela ascensão popular, não era dado; era preciso disputar os seus resultados.

Assim, suas propostas de educação popular, principalmente voltadas para a alfabetização de adultos, tinham como sentido suas noções de desenvolvimento e democracia (id. ibid., p. 89). A alfabetização seria um instrumento para possibilitar aos setores populares que emergiam a condição de sujeitos da democracia e do desenvolvimento independente do Brasil. Isto é, Paulo Freire partilhava de um projeto político de aprofundamento da democracia no país para além dos moldes estabelecidos; projeto este que, independente de críticas possíveis, foi violentamente inviabilizado pelo golpe militar.

Por outro lado, em Pedagogia do Oprimido há uma mudança que parece substancial nesse sentido. As reflexões sobre educação desenvolvidas por Paulo Freire nesse livro estariam mais ligadas a um projeto de transformação direta das estruturas sociais, indo além de uma democratização de instituições políticas. Sem abandonar jamais seus princípios democráticos e sem negar suas reflexões anteriores, Paulo Freire parece mais aprofundar questões e, a partir disso, pensar uma educação com necessidades e objetivos para um processo de transformação radical, os quais estariam inseridos no novo momento histórico vivido pelo autor: seu exílio e experiências de educação popular no Chile. 
De modo geral, a diferença seria que a Pedagogia do Oprimido deveria ser uma educação de humanização do oprimido a partir da exigência radical de que este seja o sujeito revolucionário da superação das relações de opressão, pois o opressor seria incapaz de ir contra seus próprios interesses desumanizadores. Freire diz: "E aí está a grande tarefa humanista e histórica dos oprimidos libertar-se a si e aos seus opressores" (id. I987, p. 3I). Se assim for, podemos reconhecer uma mudança qualitativa na concepção de tarefas históricas, políticas e sociais e de sujeito histórico e, dessa forma, do projeto de educação proposto entre as duas obras. Entretanto, podemos perceber também permanências em linhas gerais, como o conceito de vocação ontológica, negando uma percepção de larga ruptura entre as duas obras.

Dito isso, é possível esclarecer melhor e mais diretamente a problemática que nos interessa: em que se centraria a crítica de Paulo Freire sobre a forma hegemônica de educação naquele momento e em que sentido se encaminhariam suas concepções ideais e práticas? A crítica de Paulo Freire tem como eixo central o que ele chama de educação bancária (id. ibid., p. 59), isto é, aquela em que o educador seria o sujeito da educação com a tarefa de transmitir um conhecimento pronto e acabado aos educandos, tratados como objetos do processo. Com base em suas reflexões acerca do ser humano e das relações de opressão, Paulo Freire caracteriza esse tipo de educação como um instrumento de desumanização e opressão, pois seria negada às pessoas envolvidas que elas fossem sujeitos de uma produção de conhecimento, reflexão e prática autênticas e, assim, teriam restringida sua condição de sujeitos de sua realidade.

Nesse sentido, o autor argumentará em favor de uma educação baseada em uma relação dialógica entre educador e educando, ambos como sujeitos do aprendizado, do conhecimento e da crítica: "Ninguém educa ninguém, ninguém educa a si mesmo, os homens se educam entre si, mediatizados pelo mundo" (id. ibid., p. 68). Pensando nessa pedagogia do oprimido, entende- se a educação libertadora como um instrumento não suficiente, mas necessário para a superação da contradição opressores e oprimidos através da busca e da luta dos próprios oprimidos por sua humanização. Isso significa que uma pedagogia do oprimido deveria ter os oprimidos como sujeitos de sua própria educação ou não seria uma pedagogia do oprimido.

Podemos, agora, elucidar de forma mais satisfatória o conceito de conscientização em Paulo Freire. Ela não pode ser entendida como uma doação do educador aos educandos, pois assim continuaria sendo uma concepção típica da educação bancária. Pelo contrário, a conscientização em Freire é justamente a tarefa de uma educação que reconheça os educandos como sujeitos de seu 
aprendizado e do mundo em que vivem, possibilitando que eles próprios se percebam nessa condição. Logo, ela só seria realizável em uma relação dialógica entre educando e educador.

A crítica de Paulo Freire, portanto, não se refere apenas à institucionalização da educação ou à própria escola enquanto forma: ela se refere à educação bancária, seja ela formal ou não, e a estrutura social e política que a sustenta. Com isso, Paulo Freire demonstra que suas concepções de educação não se limitam e nem podem se limitar apenas a um projeto institucional e formal de educação e, ao mesmo tempo, considera necessário disputar politicamente nas condições dadas por uma educação libertadora e humanista.

Não se trata, por exemplo, de pensar meramente em uma reforma do modelo escolar - embora pareça ser fundamental para o autor a atuação de educadores humanistas, como ele nomeia, nos espaços institucionais buscando construir possibilidades (id. ibid., p. 62). Trata-se de pensar e atuar sobre as condições históricas, as formas de educação existentes e a possibilidade de desenvolver novas formas sem esperar imovelmente por uma transformação futura da sociedade.

Aqui é importante a diferenciação feita por Paulo Freire entre "educação sistemática" e "trabalhos educativos": respectivamente, a primeira só poderia ser mudada através da disputa e conquista do poder pelos oprimidos; os segundos poderiam e deveriam ser realizados no processo de organização dos oprimidos (id. ibid., p. 4I). A amplitude da concepção de educação de Freire fica muito clara, também, quando ele defende o "sentido pedagógico" que o processo revolucionário deveria ter (id. ibid., p. 55). Por fim, as experiências dos círculos de cultura indicam essa busca por alternativas para além da educação formal que possibilitassem uma educação libertadora e também uma crítica ao modelo escolar, ao menos na sua forma dominante: "Assim, em lugar de escola, [...] lançamos o Círculo de Cultura. Em lugar de professor, [...] o Coordenador de Debates. Em lugar de aula discursiva, o diálogo. Em lugar de aluno, [...] o participante de grupo" (FREIRE I974, p. I03).

Desse modo, mesmo reconhecendo uma necessidade de atuação na educação formal explorando suas possibilidades, a crítica aos limites impostos por esta em uma sociedade historicamente estruturada em opressões e no poder político dos opressores - definindo assim uma educação sistêmica com sentido político de manutenção da opressão - é fundamental no pensamento desenvolvido nos dois livros aqui tratados. Significando, dessa forma, que a educação formal naquele momento histórico estaria em íntima relação com o projeto político dominante, sustentando a educação bancária, e por isso é engendrada na crítica. 


\section{Convergências e divergências}

Muito comumente Paulo Freire e Ivan Illich são colocados em oposição por conta de seus respectivos conceitos e propostas sintetizados como conscientização $\times$ desescolarização. Apesar de essa dicotomia refletir o estudo central de cada um dos autores enquanto solução para os descaminhos da educação, eles não necessariamente se encontram em um caráter contraditório. Assim, por outro lado, ambos entendiam o debate pedagógico enquanto portador de uma natureza política, não podendo, portanto, manter-se fechado unicamente na forma escolar.

Ao contrário do que se costuma difundir acerca do pensamento de Illich, sua tese central não vislumbrava enquanto solução para a problemática escolar uma "sociedade sem escolas", e sim uma sociedade "desescolarizada" (ILLICH I990, p. I5 $)^{4}$ - em que não fôssemos escravos das instituições escolares e não vivêssemos a serviço de seus interesses, mas que pudéssemos, contrariamente, ter livre acesso aos instrumentos, de modo que estes não fossem mais monopolizados pelos técnicos.

Freire, por sua vez, entende a educação como um processo permanente, de modo que a escola é apenas mais uma das possibilidades de troca do conhecimento, associada às vivências cotidianas de cada indivíduo. Desse modo, quando Illich o questiona acerca da desescolarização, Freire argumenta que, para ele, essa concepção é historicamente impossível (FREIRE; ILLICH I975, p. 3I).${ }^{5}$ Assim, Freire não propõe a eliminação do modelo escolar, apesar de questioná-lo, juntamente com seus objetivos e sua forma de ensino. Sua tese central, por outro lado, reforça o intuito de uma transformação social para a qual uma educação libertadora teria papel crucial.

Dessa forma, há uma convergência no sentido de que a opressão seria tributária da existência de mitos dominantes, servindo como justificativas e naturalizações, e escondendo seus condicionamentos históricos. Das relações entre os mitos criticados pelos autores, podemos citar, por exemplo, o mito de que o conhecimento seria "posse" de determinado grupo social (no caso de Freire) ou instituição (no caso de Illich). Para Freire, haveria o mito dominante de que o conhecimento seria algo passível de ser possuído por alguém,

4 Neste artigo, Illich deixa claro que quando escreveu La sociedad desescolarizada "não auspiciava a eliminação da escola [...]. Na realidade, o livro auspiciava a desinstitucionalização da escola."

5 Segundo Freire, "En la historia hacemos lo históricamente posible y no lo que desearíamos hacer". 
como um objeto, e que, por isso, seria possível a transferência desse conhecimento de uma pessoa à outra (característica essencial da citada "educação bancária"), mitificando assim a própria realidade. Já para Illich, o mito, nesse sentido do conhecimento, seria de que este deveria ser necessariamente monopolizado pelas instituições de educação formalizada, negando ao ser humano sua capacidade individual de aprender através de suas experiências e raciocínios autônomos.

Com isso, estava claro para os dois autores que os modernos sistemas educacionais contribuíam fundamentalmente e, sobretudo, para a continuidade da condição de opressão dos seres humanos. Entretanto, enquanto Freire defendia que a educação era como um subsistema dependente das estruturas políticas e econômicas na qual se encontra, Illich acreditava veementemente que a educação não era uma variante que dependia de outras estruturas, de modo que a desescolarização se fazia fundamental dentro de um projeto político revolucionário.

A educação autoritária na qual o conhecimento estaria monopolizado, a naturalização dessa educação eminentemente opressora e as estruturas sociais e institucionais responsáveis por sustentar a dominação do ser humano estão no cerne das críticas dos dois autores. Chegando até mesmo, em certo momento, a criticar a própria noção de "educação", no caso de Illich (ILLICH I975, pp. 39-40) torna-se muito claro em ambos que os processos de aprendizagem, elaboração de conhecimentos etc. estão muito além da escola e da educação formal.

A educação, dessa forma, estaria muito mais atrelada às diversas dinâmicas da vida social e do ser humano. Seja ligada às experiências individuais em concepções de ser humano e aprendizagem autônomas visando uma sociedade sem determinações de uns a outros (Illich), seja mais ligada à política, em um sentido de construção coletiva do mundo de forma livre, solidária e democrática possibilitando a criação e a recriação de autonomia a todas as pessoas (Freire), a educação não é vista e mitificada como uma entidade fora da realidade humana. Pelo contrário, ela existiria integrada à realidade social e também às subjetividades da existência e da vivência humana.

Além disso, os dois autores parecem carregar, cada um a sua maneira, influências teológicas em suas concepções de ser humano, mesmo que subentendidas. Advindas das próprias formações pessoais de ambos, essas influências explicam, em parte, a ideia convergente de que o ser humano é dotado de certas vocações e características essenciais necessárias para sua realização. As críticas às situações de opressão partem desse fundo comum, pois a opressão seria fundada como negação dessas vocações humanas. 
Assim, Freire e Illich reconhecem também de forma semelhante que podemos estar em situação de humanização ou de desumanização, a depender das condições sociais e históricas - embora haja diferenças entre eles sobre os critérios e formas de definir essas condições. A humanização seria a possibilidade de realizar essas vocações, enquanto a desumanização seria a proibição e o impedimento de fazê-lo.

A principal diferença está no que os autores entendem sobre como ocorre o processo de dominação. Para Freire, a dominação é sempre do homem sobre o homem, do opressor sobre o oprimido, que perpetua as relações de desigualdade, juntamente com a estrutura econômica e social do sistema capitalista. Para Illich, por sua vez, a relação de opressão na sociedade contemporânea, antes de ser entre os homens, se estabelece entre os homens e as ferramentas, de modo que o homem se torna um escravo dos instrumentos. Isso define uma segunda diferença, que é como os dois enxergam o sujeito. Enquanto Freire defende o homem como sujeito histórico, único capaz de realizar a transformação, Illich retira essa característica de sujeito do homem enquanto ele está dominado pelas ferramentas, pois não consegue atuar na transformação enquanto escravo dos instrumentos de produção.

Depois, Freire defende que o ser humano, enquanto sujeito, estabelece sua relação com o conhecimento mediatizado pelo mundo em construção coletiva de conhecimento entre os homens; não descartando a autonomia de cada um na busca pelo conhecimento, mas enfatizando que este não pode ser somente individual. Para Illich, a construção do conhecimento se faz de forma mais autônoma, em que o sujeito deve ir buscar individualmente o que deseja aprender, podendo, à escolha, obter parceiros em sua busca. Mesmo assim, ela é essencialmente individual. Todavia, ambos concordam que o conhecimento está na vivência com o mundo e com as inúmeras formas de aprendizado.

Ademais, suas concepções de aprendizado também são distintas. Freire acredita que o aprendizado ocorre através da conscientização do homem, em que este se encontre inserido em sua realidade, se identifique com ela e possa assim compreender suas dinâmicas, contribuindo para abrir caminhos de transformação. Illich, por sua vez, defende que o aprendizado só poderá acontecer realmente com a desinstitucionalização da escola, visto que seu caráter institucional impede o acesso às ferramentas que permitem o conhecimento para a maior parte das pessoas, criando um mundo de especialistas.

Por fim, eles pensaram perspectivas distintas entre si a respeito da problemática da transformação das sociedades contemporâneas. Enquanto para Freire ela faz parte de um processo de busca permanente, em que a construção da consciência e a luta política sejam contínuas, para que o oprimido seja 
Limites e possibilidades da educação formal

sujeito da transformação ao mesmo tempo em que se torna consciente da necessidade dela, para assim poder superar a relação de opressão e possibilitar a humanização; para Illich, a transformação só se dará com a crise do modo de produção industrial, momento em que os homens, por consenso, promoverão sua inversão, libertando-nos, dessa forma, através do fim do monopólio do saber, garantindo um acesso igualitário às ferramentas.

\section{v. Conclusão}

A emersão de diversificadas matizes críticas aos modelos de educação tradicionais serão marcas, de modo geral, dos debates no século XX, principalmente em sua segunda metade. As interpretações de que haveria uma crise da educação, em seus diversos âmbitos, aparecem fortalecidas. Desse modo, Paulo Freire e Ivan Illich inserem-se em um cenário no qual perspectivas questionadoras sobre a educação moderna já estavam sendo lançadas com significativa aceitação e abriam vias de se consolidarem.

Grandes autores do século passado, como Hannah Arendt, Theodor Adorno e Michel Foucault já publicizavam, no período, contribuições acerca dessa temática e são bons exemplos da variedade de vertentes que se estabeleciam. Mais recentemente, autores como István Mészáros e Regina Magalhães de Souza continuam elucidando questões similares sobre a crise da escola; existindo, portanto, há quase um século, uma continuidade nesse debate.

Contudo, Freire e Illich foram também pensadores que colaboraram com esses movimentos críticos e seus avanços. Eles foram parte de uma geração que, tentando superar os limites e os impasses da crise, procurava respostas e possibilidades através de formulações inovadoras. Talvez possamos entender as íntimas relações entre as convergências e, ao mesmo tempo, as contraposições radicais das divergências entre os dois autores na seguinte chave: mesmo que eles estivessem lidando com problemáticas semelhantes da crise, eles procuraram, por outro lado, resoluções criativas. Foram, inegavelmente, pensadores que não se acomodaram em uma zona de conforto, mas sim arriscaram interpretações, perspectivas críticas e alternativas, almejando estar à altura dos desafios colocados. Este é, possivelmente, um aspecto relevante para compreender as intensas repercussões internacionais de suas obras naquele momento histórico.

Nesse sentido, Paulo Freire foi responsável por uma produção e prática que se destacam pela valorização de projetos educacionais inseridos na realidade do educando, respeitando as diversidades humanas. Crítico in- 
cisivo da ideia de neutralidade na educação, ele defendia que as diferentes formas de educação correspondem a determinados objetivos e necessidades, isto é, a educação estaria profundamente atrelada à práxis humana e, portanto, não deveria ser mitificada. Contra fórmulas prontas e modelos petrificados, apostou em novas formas e métodos de aprendizagem, que possibilitassem ao educando se revelar enquanto sujeito histórico e adquirir sua autonomia.

Ivan Illich, por sua vez, foi inovador no sentido de, juntamente com Reimer, ser o primeiro escritor a questionar a institucionalização da escola e os seus desserviços para o processo de aprendizagem. Para ele, ela seria uma restrição violenta a aprendizagem do indivíduo, pois, através da monopolização do saber - a qual as instituições escolares são as principais responsáveis -, negaríamos as capacidades inerentes ao ser humano. Assim, afirmou a autonomia individual que todos teríamos para a construção do nosso próprio saber, sem depender, necessariamente, das escolas.

Por fim, pode-se questionar se há alguma atualidade nas contribuições dos autores nessa discussão. Para tanto, é necessário pensar se essas questões já estão superadas. Considerando que ainda hoje, em grande parte das sociedades, as possibilidades de aprendizado continuam desiguais - mesmo com a expansão da escola -, nos parece claro que os modelos de educação formal existentes se mostram incapazes de possibilitar um aprendizado que respeite as diversidades humanas, a autonomia e a criatividade do indivíduo e que não esteja desvinculado da sua realidade.

Nesse sentido, Freire e Illich permanecem fundamentais nessa discussão, tanto para pensar os problemas já levantados no século XX - e ainda não superados -, quanto para nos auxiliar a resolver as novas problemáticas emergentes. Isso significa que não devemos desconsiderá-los, mas que, por outro lado, não devemos transpor automaticamente suas formulações. Assim, partindo criticamente de suas ideias e dando novos significados a eles em nosso espaço-tempo, poderemos descobrir antigas facetas dessa problemática para, quem sabe, destrinchar os limites da educação formal e angariar novas possibilidades de transformá-la.

Em tempos de determinações tecnocráticas, recrudescimento de lógicas privatizantes e redução dos espaços políticos na educação e em outras dimensões de nossas sociedades, mantém-se necessário um esforço para desnaturalizar práticas e modelos instituídos. Desse modo, Paulo Freire e Ivan Illich parecem apontar direções promissoras para repensarmos as formas de atuação educativa e sua organização, tendo em vista transpassarmos os impasses e os limites das formas atualmente estabelecidas. 


\section{Referências bibliográficas}

ADORNO, Theodor. Educação e emancipação. São Paulo: Paz e Terra, 2010.

ARENDT, Hannah. A crise da educação. In Entre o passado e o futuro. São Paulo: Perspectiva, 2005 .

FOUCAULT, Michel. Vigiar e punir. Petrópolis: Vozes, 2012.

FREIRE, Paulo. Educação como prática da liberdade. Rio de Janeiro: Paz e Terra, I967. Pedagogia da Autonomia. São Paulo: Paz e Terra, 2002. Pedagogia da Esperança. Rio de Janeiro: Paz e Terra, 2009. Pedagogia do Oprimido. Rio de Janeiro: Paz e Terra, $201 \mathrm{I}$.

FREIRE, Paulo; ILLICH, Ivan. Diálogo: Paulo Freire e Ivan Illich. Buenos Aires: Búsqueda, I975.

ILLICH, Ivan. La sociedad desescolarizada. In Obras reunidas. Cidade do México: Fondo de Cultura Económica, 2006, v. I.

. La convivencialidad. In Obras reunidas. Gidade do México: Fondo de Cultura Económica, 2006, v. I.

$\mathrm{Na}$ ilha do alfabeto. In Educação e liberdade. São Paulo: Imaginário, I990.

MÉSZÁROS, István. A educação para além do capital. São Paulo: Boitempo, 2005.

OLIVEIRA, Rosiska; DOMINICÉ, Pierre. Ivan Illich e Paulo Freire: a opressão da pedagogia, a pedagogia dos oprimidos. Lisboa: Sá da Costa, I977.

PETITFILS, Jean-Christian. Ivan Ilitch: a convivialidade. In __. Os socialismos utópicos. São Paulo: Círculo do Livro, I977.

SOUZA, Regina Magalhães de. Escola e juventude: o aprender a aprender. São Paulo: Educ/Fapesp/Paulus, 2003.

Roberta Baessa Estimado - Graduanda em História pela Universidade de São Paulo.

roberuta@gmail.com

João Luís Lemos de Paula Santos - Graduando em História pela Universidade de São Paulo.

joão.luis.santos@usp.br 